\title{
EXPERIMENTAL AND ANALYTICAL INVESTIGATION OF THERMAL PARAMETERS DEVELOPED IN HIGH CARBON STEEL JOINTS FORMED BY GTA WELDING
}

\author{
J. Dutta ${ }^{*}$ and Narendranath S. \\ Department of Mechanical Engineering, National Institute of Technology Karnataka, Surathkal, India \\ ${ }^{*}$ Corresponding e-mail: duttajd1212@gmail.com
}

\begin{abstract}
This investigation reveals an elaborate analysis of variation of thermal properties of high carbon steel plate butt joints formed by DC Gas Tungsten Arc (GTA) welding. Experiment has conducted to predict the two dimensional temperature cycle developed. To find out the heat flux distribution, Gaussian Heat source model has been implemented. Carslaw-Jaeger's mathematical model has been incorporated to estimate the variation of thermal conductivity. To portray the change in specific heat at different locations from the fusion boundary at experimental temperatures, Thin plate model has been utilized. Heat loss due to convection, radiation and evaporation have been studied. To estimate total heat loss from weld joint at different locations a method has been proposed and Vinokurov's empirical correlation has been used for validation. At very close region (36mm from fusion boundary) to heat affected zone all thermal properties have shown significant variation based on experimental results. From the analysis of heat loss an optimum temperature has been observed and it is helpful to define the range of convection and radiation heat loss phenomena.
\end{abstract}

Keywords: GTA welding, Thermal cycle, Gaussian heat source model, Heat loss.

\section{INTRODUCTION}

Due to several advantages than other processes, Gas Tungsten Arc Welding (GTAW) is one of the important fusion welding process which finds extensive applications such as shipbuilding and naval industries, aircraft manufacturing, automobile parts making, atomic energy instruments etc. Because of less spatter, sound weld and better control, GTAW is presently utilized in a wide manner for both ferrous metals such as medium and high carbon steels and their alloys, as well as non-ferrous metals such as aluminum, copper and magnesium alloys. In this process flow of inert gas (such as argon, helium, nitrogen etc.) shields the tungsten electrode and workpiece is joined by voltaic arc generated due to a moving point heat source and with the help of filler material. The fusion consists of localized heating, melting and solidification of parent metals. Therefore a rapid, non-uniform heat flow is propagated through the weld pool due to electrode movement. The thermal expansion and subsequent contraction result as vigorous change in metallurgical as well as mechanical properties.

Thus an elaborate study of thermal behaviour (especially at high temperatures) is very essential for selecting the suitable design parameters to produce a sound and reliable structure. There is a continuous effort by the designers to investigate the thermal cycle produced in fusion welding to optimize the thermal parameters. The first powerful analytical model for estimating temperature distribution and its effect on other thermophysical properties have been developed by Rosenthal ${ }^{1}$. Though it is very popular for analyzing the thermal phenomena, but this model is not valid for estimating properties at higher temperature due to its quasi-steady state assumptions. The heat source presented in Rosenthal's model was localized line heat source. Pavelic et al. ${ }^{2}$ first proposed the heat source as Gaussian distribution manner while propagating from moving point heat source. Appreciable work has been reported by Goldak et al. ${ }^{3,4}$ assuming Pseudo-Gaussian heat source and the analytical model has been validated by experimental results. Little and Kamtekar $^{5}$ investigated the transient thermal properties in connection with weld efficiency. An elaborate research work has been devoted to find out the analytical solution of temperature rise of short pieces based on Carslaw-Jaeger's moving point heat source model and comparative study with finite element method have been reported by Komanduri and $\mathrm{Hou}^{6,7}$ and also introduced heat flux distribution as instantaneous ring heat source. Gery et al. ${ }^{8}$ used Goldak's double ellipsoidal model to find out the effect of welding speed, energy input and heat source distribution on temperature variation. Poorhaydari et al. ${ }^{9}$ determined peak temperature and cooling rate of different plate thickness with an innovative method and also have validated with empirical models. Mousavi and Miresmaeili ${ }^{10}$ studied effect of conduction, convection and radiation on temperature dependent material properties for 304L stainless steel joints prepared by GTA welding, taking account combined thermal conductivity with Gaussian heat source distribution. Goncalves, Carvalho and Guimaraes ${ }^{11}$ applied implicit finite difference method to determine temperature fields at any region at any instant of the welded plate from the estimation of heat rate delivered to the workpiece. For thin welding plates finite element model has been implemented by Attarha and Sattari ${ }^{12}$ to estimate temperature distribution for different induced heat source. Pathak et al. ${ }^{13}$ suggested a new method to calculate temperature cycle in accounting of 
both convection and radiation heat loss for multipass arc welding. Tong et al. ${ }^{14}$ proposed time dependent dynamic welding heat source model to describe heat flux distribution in pulsed current GTAW and also experimentally judged the parameters to validate the analytical results. Dal et al. ${ }^{15}$ presented estimation of time evolution based on iterative regularization method in spot GTA welding. The solid phase and melted region has been studied by macrograph to investigate effect of heat source. Ravisankar A. et al. ${ }^{16}$ evaluated temperature distribution based on numerical simulation and experimental work of AISI 304 stainless steel joints prepared by GTAW. Heat source data fitting has been carried out to optimize the heat input at particular electrode velocity in heat affected zone (HAZ).

From the detailed literature survey summarized above, it is clear that to estimate the thermal properties the selection of heat source distribution is very important as it will determine the variation of thermophysical properties involved in moving point heat source. Motivated by these studies present work has been undertaken to identify the thermal variables such as thermal conductivity, specific heat, thermal cycle, heat loss in different ways have been analyzed with time variation along the weld pool as well as its effect on longitudinal direction from the fusion boundary.

\section{MATHEMATICAL MODEL IMPLEMENTED FOR THERMAL ANALYSIS}

The heat source distribution has been estimated by implementing the Gaussian surface heat flux which mathematically yields ${ }^{17}$ :

$$
\mathrm{q}(\mathrm{x}, \mathrm{z}, \mathrm{t})=\frac{3 \mathrm{Q}}{\pi \mathrm{r}_{\mathrm{b}}^{2}} \exp \left[-\frac{3\{\mathrm{x}+\mathrm{vt}\}}{\mathrm{r}_{\mathrm{b}}^{2}}\right] \exp \left(\frac{3 \mathrm{z}^{2}}{\mathrm{r}_{\mathrm{b}}^{2}}\right)
$$

Where, $Q=\eta V I$ is denoted as heat input (w) and ' $r_{b}$ ' is radius $(\mathrm{mm})$ of moving heat flux, ' $\mathrm{x}$ ' and ' $\mathrm{z}$ ' are space coordinates (refer Fig. 1), ' $t$ ' indicates the total time of welding, ' $\mathrm{V}$ ' is voltage of welding transformer, ' $\mathrm{I}$ ' is current provided from welding transformer (refer Table 4), ' $\eta$ ' is heat transfer efficiency.

Temperature distribution along the weld pool i.e. $\mathrm{x}$ direction as well as longitudinal direction from weld pool i.e. $\mathrm{z}$ direction has been portrayed based on this model (refer Fig. 1).

To find out the variation of specific heat, thin plate model for temperature cycle as provided by Poorhaydari et al. ${ }^{18}$ and it can be furnished as follows:

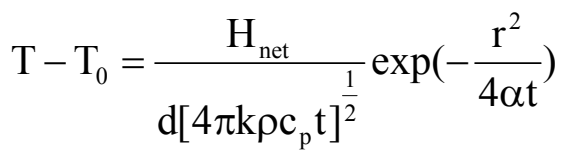

Where, $H_{n e t}=\frac{\eta V I}{v}$ is net heat transfer $(\mathrm{J} / \mathrm{mm})$ and $\mathrm{r}=\sqrt{\mathrm{x}^{2}+\mathrm{y}^{2}+\mathrm{z}^{2}}$ is the radial distance $(\mathrm{mm})$ in surface of weld metal, ' $\mathrm{T}$ ' is peak temperature at particular location, ' $\mathrm{T}_{0}$ ' is ambient temperature, ' $\mathrm{d}$ ' is plate thickness, ' $k$ ' is thermal conductivity, ' $\rho$ ' is density of base metal, $\mathrm{C}_{\mathrm{p}}$ is specific heat of base metal. To determine the changes in thermal conductivity and its impact on different zones of weld plate due to movement of arc, Carslaw-Jaeger's linear mathematical model for moving point heat source ${ }^{18}$ has been introduced in this analysis and it can be written as:

$$
\theta=\frac{\mathrm{Q}_{\mathrm{pt}}}{4 \pi \mathrm{kr}} \exp \left[-\frac{\mathrm{V}}{2 \alpha}(\mathrm{x}+\mathrm{r})\right]
$$

Where $\theta$ is temperature rise (difference between peak temperature and ambient temperature), $\mathrm{Q}_{\mathrm{pt}}$ is heat $\operatorname{input}(\mathrm{w}), \alpha$ is thermal difussivity, $\mathrm{Q}_{\mathrm{pt}}$ is $\mathrm{Q}_{\mathrm{pt}}=\eta \mathrm{VI}$.

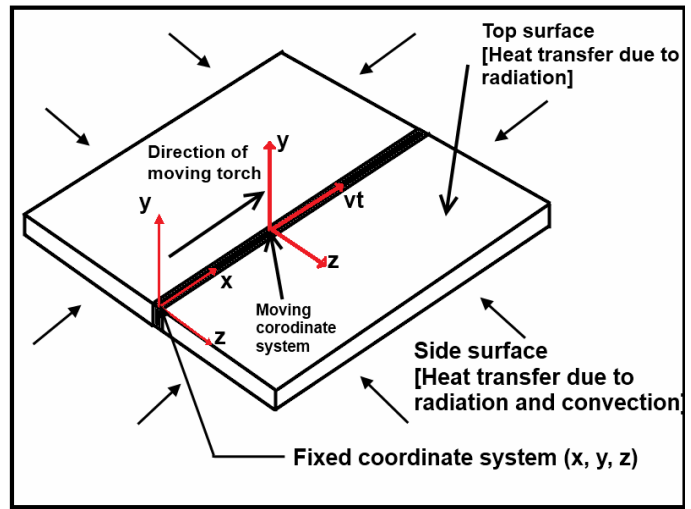

Figure 1. Schematic diagram of moving point heat source in GTAW.

important role to define the width of heat affected zone.

The convective heat loss can be formulated $\mathrm{as}^{14}$ :

$\mathrm{Q}_{\text {conv }}=\mathrm{A}_{\text {surface }} \mathrm{h}_{\mathrm{c}}\left[\mathrm{T}_{\mathrm{P}}-\mathrm{T}_{0}\right]$

Where, $A_{\text {Surface }}$ is surface area of weld specimen, $h_{c}$ is convective heat transfer coefficient, $\mathrm{T}_{\mathrm{P}}$ is peak temperature and $\mathrm{T}_{0}$ is ambient temperature.

The Radiation heat loss can be expressed as ${ }^{14}$ :

$$
\mathrm{Q}_{\mathrm{rad}}=\mathrm{A}_{\text {surface }} \varepsilon \sigma\left[\mathrm{T}_{\mathrm{P}}^{4}-\mathrm{T}_{0}^{4}\right]
$$

Where, $\varepsilon$ is emissivity of the weld surface, $\sigma$ is Stefan's Boltzmann constant (refer Table 4)

The evaporation heat loss can be mentioned as ${ }^{19}$ :

$\mathrm{Q}_{\text {evap }}=\mathrm{A}_{\text {Surface }} \omega \mathrm{H}_{\mathrm{v}}$

Where, $\omega$ is rate of vaporization $\left(\mathrm{kg} \cdot \mathrm{s}^{-1} \cdot \mathrm{m}^{-2}\right)$ and $\mathrm{H}_{\mathrm{V}}$ is heat of vaporization $(6300 \mathrm{~kJ} / \mathrm{kg}$ for steel).

The mathematical expression for rate of vaporization is given as ${ }^{19}$ :

$\omega=\exp \left[A-\frac{B}{T}-0.5 \ln (T)+C\right]$ 
In equation (7), $\mathrm{A}, \mathrm{B}$ and $\mathrm{C}$ are empirical coefficients (For steel, $\mathrm{A}=12.63, \mathrm{~B}=20000, \mathrm{C}=-3.36$ ) and $\mathrm{T}$ is temperature at particular point of interest.

In this paper a technique has been suggested to determine the total heat loss at different locations and mathematically it can be as follows:

$$
\mathrm{Q}_{\text {Total }}=\mathrm{A}_{\text {Surface }}\left[\mathrm{h}_{\mathrm{c}}\left(\mathrm{T}_{\mathrm{P}}-\mathrm{T}_{0}\right)+\varepsilon \sigma\left(\mathrm{T}_{\mathrm{P}}^{4}-\mathrm{T}_{0}^{4}\right)+\omega \mathrm{H}_{\mathrm{v}}\right]
$$

For validation of equation (8), Vinokurov's empirical model $^{22}$ of combined convective-radiation heat transfer coefficient (conjugate heat transfer) has been utilized as:

$$
\mathrm{h}_{\text {vino }}=2.41 \times 10^{-3} \varepsilon \mathrm{T}^{1.61}
$$

The rate of heat loss based on equation (9) can be given as:

$$
\mathrm{Q}_{\text {Total }}^{\prime}=\mathrm{A}_{\text {Surface }} \mathrm{h}_{\text {vino }}\left(\mathrm{T}_{\mathrm{P}}-\mathrm{T}_{0}\right)
$$

\section{EXPERIMENTAL WORK}

Experimental work has been carried out to predict the temperature cycle developed in weld joint. Five thermocouples have been inserted (refer Fig. 2) on the surface of the plate maintaining $30 \mathrm{~mm}$ distance each along the longitudinal direction from the fusion boundary (refer Fig. 3 ). Table 1 denotes the chemical composition of AISI 1090.

Table 1. Chemical composition of AISI $1090^{6,7,23}$

\begin{tabular}{llllll}
\hline Element & $\mathrm{C}$ & $\mathrm{Fe}$ & $\mathrm{Mn}$ & $\mathrm{P}$ & $\mathrm{S}$ \\
Percentage & 0.85 & $98.03-$ & $0.60-$ & 0.040 & 0.050 \\
(\%) & - & 98.55 & 0.90 & & \\
& 0.98 & & & & \\
\hline
\end{tabular}

Table 2. Details of instruments used for experiment

\begin{tabular}{ll}
\hline Specimen & Material: AISI 1090 \\
& Dimension: $180 \times 60 \times 10 \mathrm{~mm}$
\end{tabular}

GTAW System Welding amperage range: 3-350A, Rated output: $250 \mathrm{~A}$ at

$30 \mathrm{~V}, 100 \%$ Duty cycle, Maximum open circuit voltage: $75 \mathrm{VDC}$

\begin{tabular}{ll}
$\begin{array}{l}\text { Data } \\
\text { Acquisition } \\
\text { System (DAQ) }\end{array}$ & $\begin{array}{l}\text { NI 9213, 16 Channel, 24bit } \\
\text { thermocouple, CAT II, Ch. To earth } \\
\text { insulation }\end{array}$ \\
Filler metal & $\begin{array}{l}\text { Copper coated triple de-oxidized mild } \\
\text { steel rod }\end{array}$ \\
Inert gas used & Argon \\
Thermocouple & K type \\
\hline
\end{tabular}

The tapped holes has been made on the surface of the plate to insert the thermocouple end. Table 2 denotes the experimental apparatus used for measurement. The rear end of the thermocouple has been connected to the Data Acquisition System to acquire the temperature at different locations for a fixed interval of time and it has simulated in LABVIEW software. The weld bead formed by GTAW and corresponding HAZ can be visualized in Fig. 4. The experimental process parameters and thermophysical properties of AISI 1090 are tabulated in table 3 and table 4 respectively.

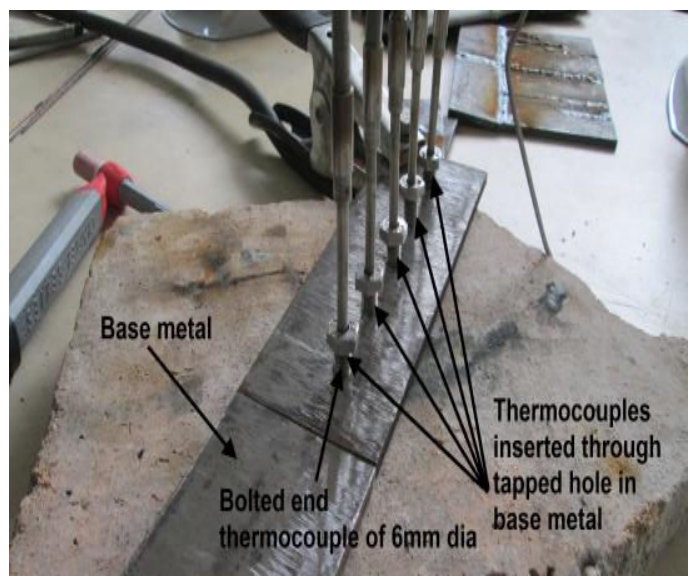

Figure 2. Five thermocouples inserted through

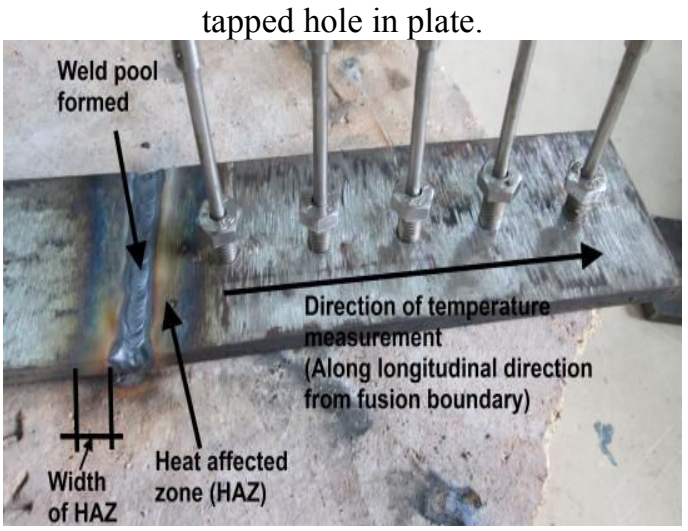

Figure 3. Weld pool formed after single pass welding.

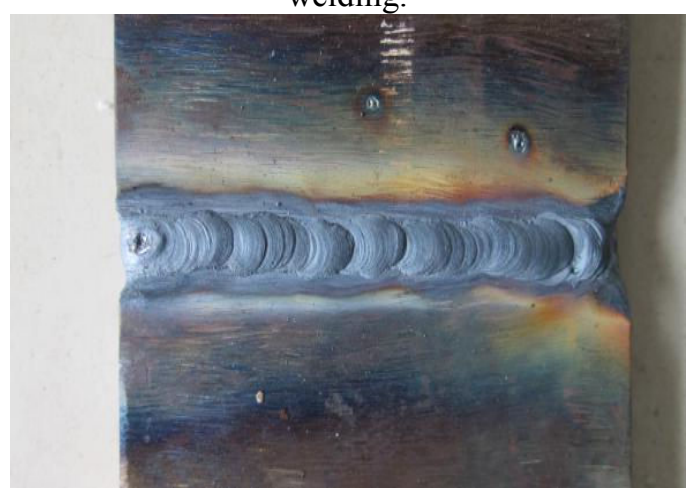

Figure 4. Broad view of heat affected zone developed in joint.

Table 3. Thermophysical properties of AISI 1090

\begin{tabular}{ll}
\multicolumn{2}{c}{$\left(\right.$ at $\left.30^{\circ} \mathrm{C}^{23}\right)$} \\
\hline Density $\left(\mathrm{kg} / \mathrm{m}^{3}\right)$ & 7790 \\
Specific heat $\left(\mathrm{J} / \mathrm{kg}-{ }^{\circ} \mathrm{C}\right)$ & 0.465 \\
Thermal conductivity $\left(\mathrm{w} / \mathrm{m}-{ }^{\circ} \mathrm{C}\right)$ & 49.8 \\
Thermal diffusivity $\left(\mathrm{m}^{2} / \mathrm{s}\right)$ & 13.74 \\
\hline
\end{tabular}


Table 4. Experimental process parameters

\begin{tabular}{ll}
\hline Input current $(\mathrm{A})$ & 150 \\
Input voltage $(\mathrm{V})$ & 12.8 \\
Time of completing single pass(s) & 70 \\
Electrode speed $(\mathrm{mm} / \mathrm{s})$ & 0.857 \\
Heat input $(\mathrm{w})$ & 1632 \\
Heat transfer efficiency $(\%)$ & 85 \\
Radius of GTAW flux $(\mathrm{mm})$ & 3 \\
Surface area $\left(\mathrm{mm}^{2}\right)$ & 10800 \\
Heat transfer coefficient $\left(\mathrm{w} / \mathrm{m}^{2}-\mathrm{K}\right)$ & 10 \\
Stefan Boltzmann constant $\left(\mathrm{J} / \mathrm{m}^{2}-\mathrm{K}^{4}\right)$ & $5.67 \times 10^{-3}$ \\
Emissivity & 0.8 \\
\hline
\end{tabular}

\section{RESULTS AND DISCUSSION}

Figure 5 denotes the experimental temperature distribution measured through data acquisition system which has acquired data from the starting of moving point heat source to till the end point for heat input of $1632 \mathrm{w}$. The total time of welding is 70 s. In Fig. 6 temperature plot has been taken upto $60 \mathrm{~s}$, as last $10 \mathrm{~s}$ denotes no variation of temperature. It has been observed that higher temperature sensed by thermocouples is in the region of $36 \mathrm{~mm}$ ( $\mathrm{T}_{1}$, first position of thermocouple from fusion boundary) and $72 \mathrm{~mm}\left(\mathrm{~T}_{2}\right.$, second position of thermocouple from fusion boundary). The reason is influence of heat affected zone formed near $\mathrm{T}_{1}$ and $\mathrm{T}_{2}$. From $108 \mathrm{~mm}$ to till end of $180 \mathrm{~mm}$ (at the position of $\mathrm{T}_{3}, \mathrm{~T}_{4}$ and $\mathrm{T}_{5}$ ), temperature distribution compared to first two points is low. This variation also point out the transient nature of temperature. The energy exchange from the liquid solid interface in fusion boundary is very rapid and it can be well justified by Fig. 5, as the time taken to attain higher temperature is very fast whereas time taken for reduction of high temperature to reach lower temperature is very gradual. This results has been compared with the analysis presented by Goncalves, Carvalho and Guimaraes ${ }^{10}$, with satisfactory discussions.

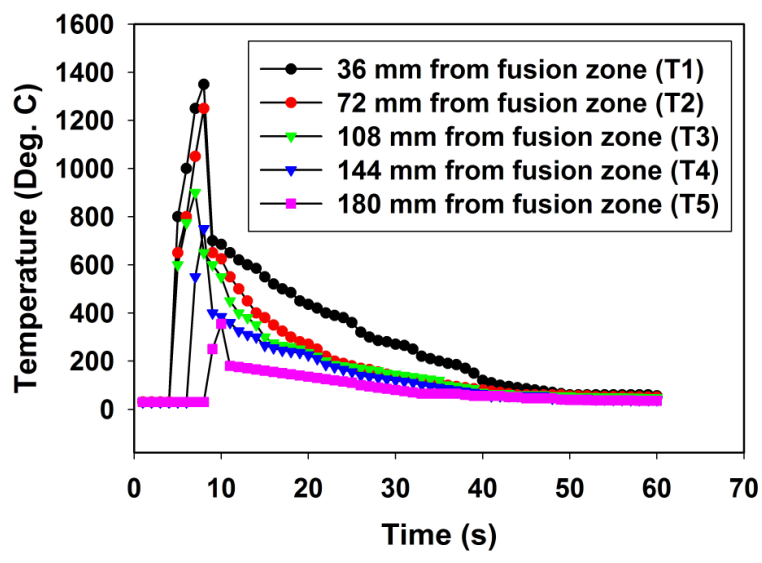

Figure 5. Experimental temperature distribution from fusion boundary to longitudinal direction.

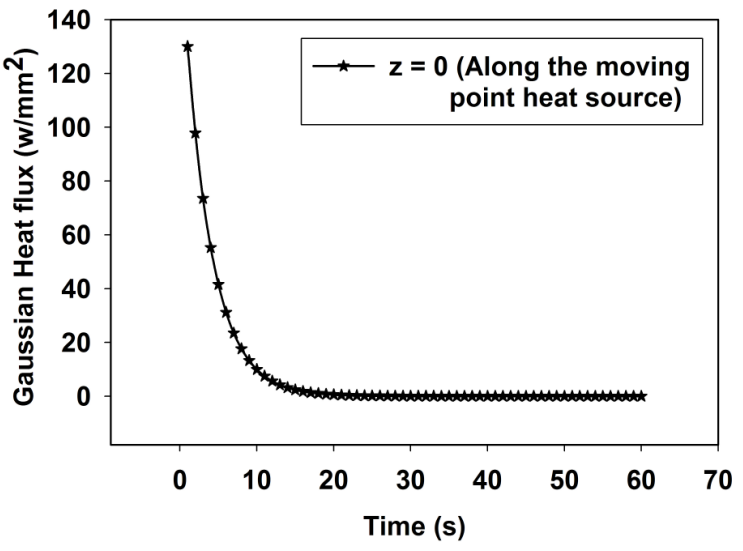

Figure 6. Variation of Gaussian heat flux along fusion boundary with movement time of electrode.

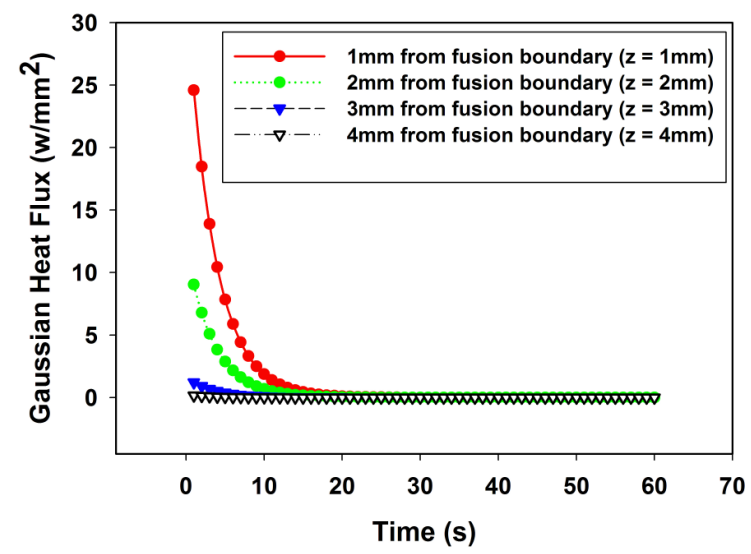

Figure 7. Variation of Gaussian heat flux along longitudinal direction from fusion boundary with movement time of electrode.

Figure 6 presents the Gaussian heat flux (refer equation 1) varies with time along the fusion boundary $(\mathrm{z}=0)$. The distribution nature of heat flux exactly matches with experimental temperature. The parameters involved in this flux distribution shows highest variation near the starting time and gradually decreases towards the end. Fig. 7 represents the heat flux variation based on Gaussian model towards the longitudinal direction of from fusion boundary (refer Fig. 1). Both Fig. 6 and Fig. 7 denotes that random change in heat flux occurs within $0-15 \mathrm{~s}$. The distance $(\mathrm{z}=1,2,3 \ldots$.$) kept as small as possible due to$ exponential terms involved in the expression of Gaussian heat flux distribution and its inability to calculate the higher order terms. Traidia and Roger ${ }^{20}$ have estimated the anodic heat flux along the weld pool as well as along the longitudinal direction and Fig. 6 and Fig. 7 have shown good agreement with their results. 


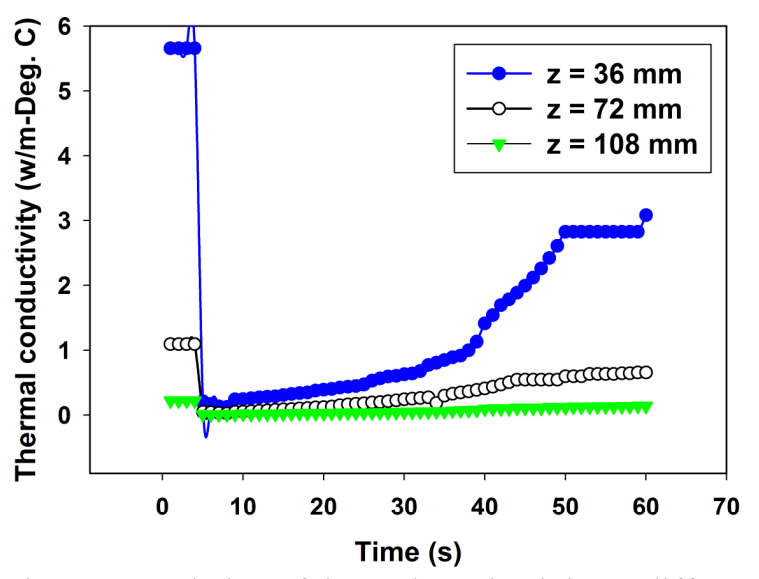

Figure 8. Variation of thermal conductivity at different locations due to temperature rise with time period.

Figure 8 has reported change in thermal conductivity at different locations with the experimental temperature measured for particular time period (for 60s) based on Carslaw-Jaeger's moving point heat source model as portrayed in equation (3). The heat input and welding velocity are kept constant. Fig. 8 follows the same trend as Fig. 6 and Fig. 7. As measured the experimental temperature, it was initially at ambient temperature and then suddenly reached the maximum (refer Fig. 5), the peak $(\mathrm{z}=36 \mathrm{~mm})$ in Fig. 8 shows thermal conductivity at ambient temperature and suddenly it has decreased to minimum as temperature suddenly raised closer to melting point. The reason is thermal conductivity of solid decreases with increase in temperature ${ }^{21}$. After $\mathrm{z}=108 \mathrm{~mm}$ the thermal conductivity shows negligible variation.

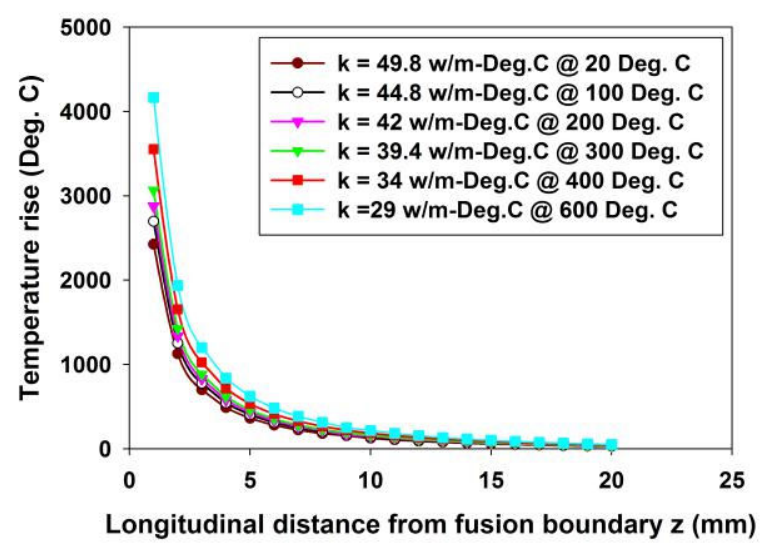

Figure 9. Variation of temperature rise towards longitudinal direction from fusion boundary for different values of thermal conductivity.

Figure 9 shows the temperature variation for different thermal conductivity along the longitudinal direction from weld pool based on equation (3). For lower thermal conductivity temperature rise is maximum and it also justifies the nature of distribution of Fig. 8. Both Fig. 8 and Fig. 9 can be well supported by the results generated by Komanduri and $\mathrm{Hou}^{6,7}$ who have also used Carslaw-Jaeger's model for investigation.

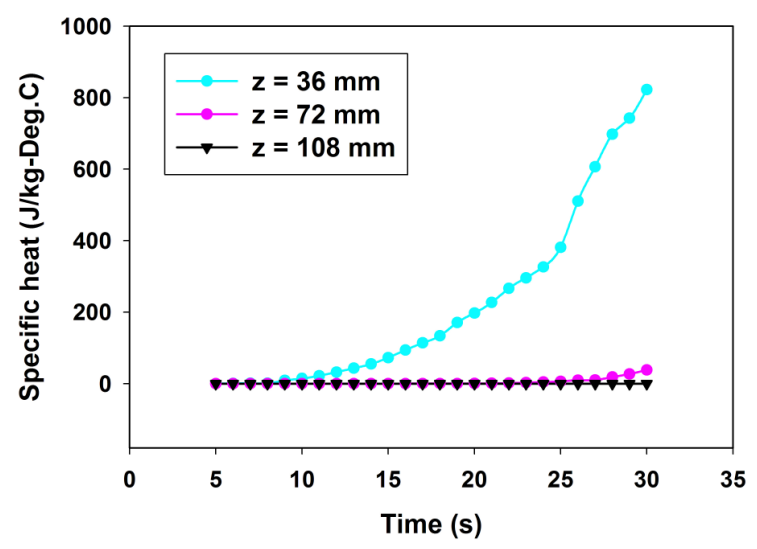

Figure 10. Variation of specific heat with time at different locations from fusion zone.

Figure 10 is defined as the change in specific heat with time at different location from the fusion boundary based on equation (2). The research work carried out by Poorhaydari et al. ${ }^{9}$ has used the mathematical expression (equation 2) to correlate the plate thickness and its importance to find out the cooling rate. In this study same expression has been utilized for estimating specific heat variation. The experimental peak temperaturse have been taken account from 5 - 30s as sensed by thermocouples as this time zone denotes the variation. It was found that at $\mathrm{z}=36 \mathrm{~mm}$, specific heat is very low and it gradually increases along with temperature loss. $\mathrm{z}=72 \mathrm{~mm}$ and $\mathrm{z}$ $=108 \mathrm{~mm}$ negligible specific heat shows negligible change due to rapid heat loss. This concept is very useful to define rate of cooling. It also defines the acceptability of equation (2) and its influence on thermal behaviour reported by Poorhaydari et al. ${ }^{9}$.

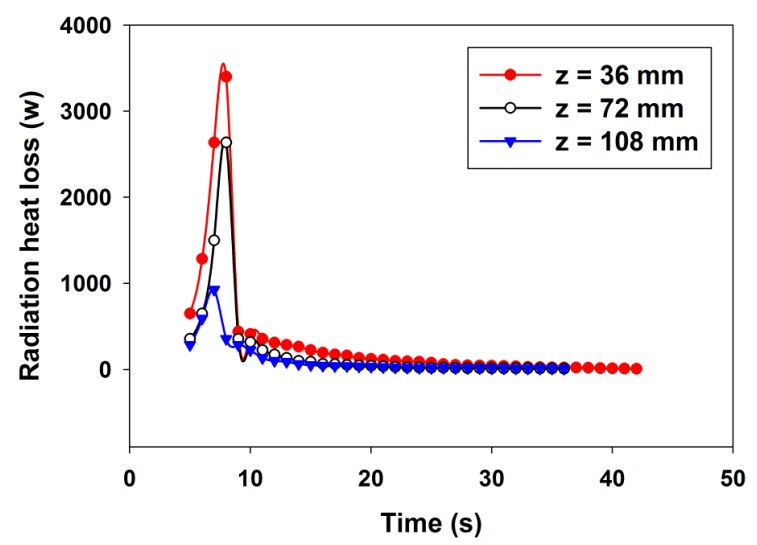

Figure 11. Radiation heat loss with time at different locations.

Heat loss from weld joint is an important phenomena as it reveals the crack propagation in surfaces. Heat loss in welding surface is an conjugative 
radiation-convection heat transfer. Proper selection of material (based on emissivity) is essential because radiation heat loss is dominates convective heat transfer ${ }^{13}$. Fig. 11 and Fig. 12 shows that radiation heat loss at higher temperature is dominating convective heat transfer. From calculation based on equation (4) and equation (5), it was studied that for experimentally measured temperature at $\mathrm{z}=36 \mathrm{~mm}, 380^{\circ} \mathrm{C}$ is an optimum temperature where radiation and convective heat loss are same $(60.70 \mathrm{w})$ and after this convective heat transfer dominates radiation heat transfer. For $\mathrm{z}=72 \mathrm{~mm}$ and $\mathrm{z}=108 \mathrm{~mm}$ the optimum temperatures are $325^{\circ} \mathrm{C}$ and $300^{\circ} \mathrm{C}$ respectively. Thus it clearly indicates that at higher temperature $\left(<400^{\circ} \mathrm{C}\right)$ radiation heat loss is sole reason for heat loss compared to convective heat transfer. For temperature range $(0$ $350^{\circ} \mathrm{C}$ ) convective heat loss can be accountable. This results can be well compared with analysis made by Pathak et al. ${ }^{13}$

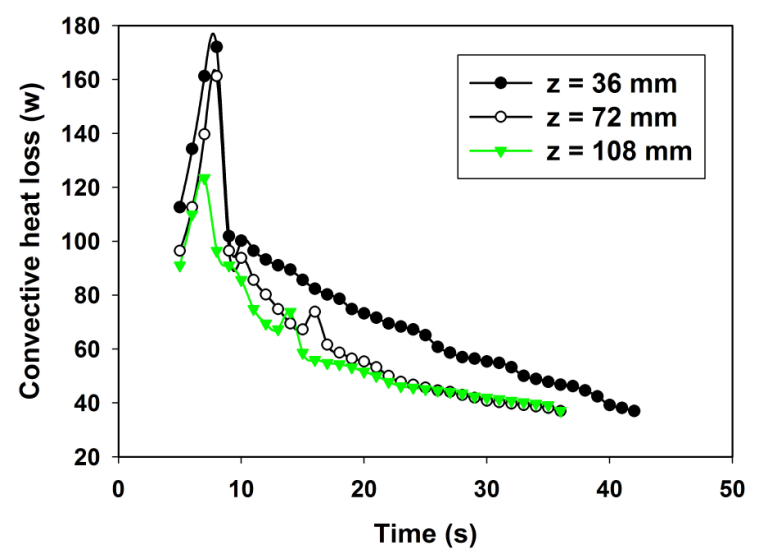

Figure 12. Convection heat loss with time at different locations.

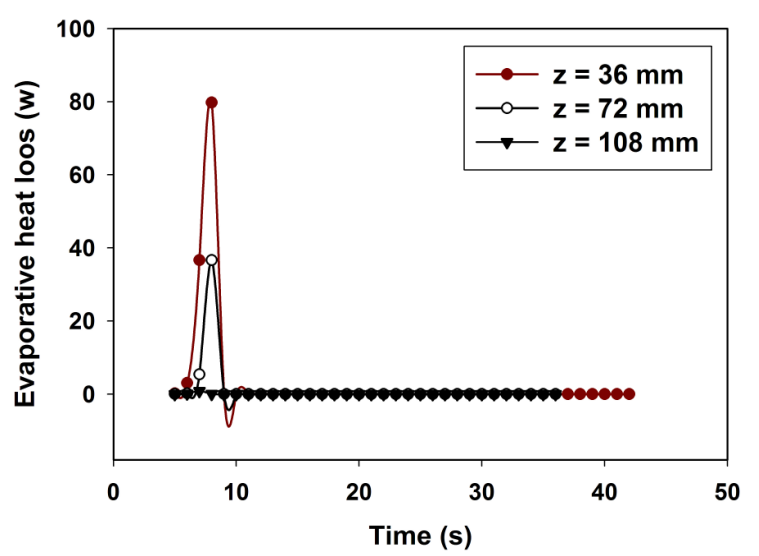

Figure 13. Evaporation heat loss with time at different locations.

Though evaporation has little role for heat transfer in welded joints but still we have considered this parameter as one of the contribution of heat loss in present study. The evaporation loss (refer equation 6 and 7) is maximum at the location near the fusion zone due to liquid - solid interface and rapid momentum exchange in fusion boundaries. Fig. 13 denotes the higher heat loss near the fusion boundary $(\mathrm{z}=36 \mathrm{~mm})$, comparatively less at $\mathrm{z}=72 \mathrm{~mm}$ and negligible at $\mathrm{z}=$ $108 \mathrm{~mm}$.

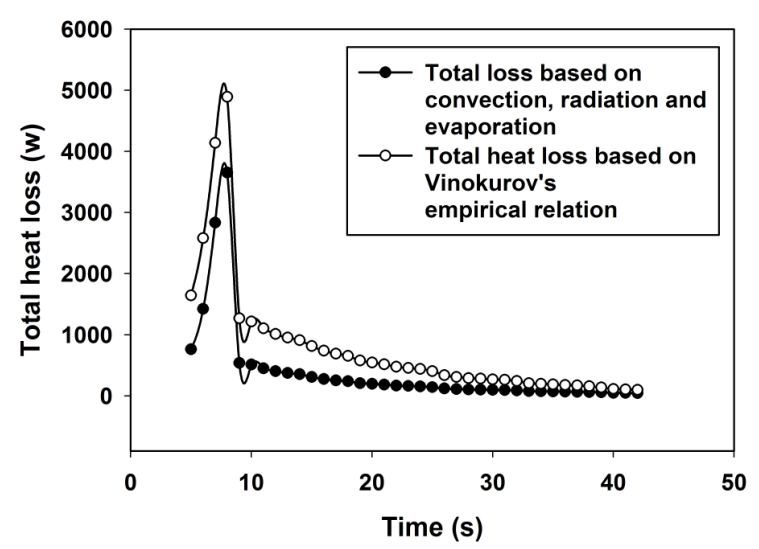

Figure 14. Comparison of heat loss due to proposed relation and empirical relation at $\mathrm{z}=36 \mathrm{~mm}$.

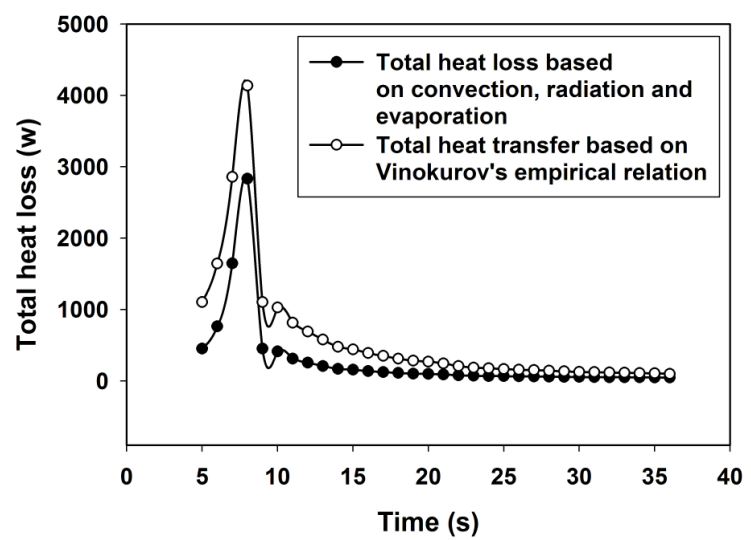

Figure 15. Comparison of heat loss due to proposed relation and empirical relation at $\mathrm{z}=72 \mathrm{~mm}$.

Figure 14 and Fig. 15 define that at low temperature proposed correlation shows good agreement with empirical correlation. But at higher temperature empirical correlation gives higher heat loss than proposed ones. This is due to combined convection-radiation involved in Viokurov's empirical relation and there is no optimum temperature as studied in present investigation. This results can be well justified by Pathak et al. ${ }^{13}$

\section{CONCLUSION}

The following remarks can be drawn from the present study:

Experimental temperature cycle for GTA welding of high carbon steel is maximum near the heat affected zone $(z=36 \mathrm{~mm}$ and $\mathrm{z}=72 \mathrm{~mm})$. At same time interval other locations $(\mathrm{z}=108,144,180 \mathrm{~mm})$ maximum 
temperature attained is very less due to rapid heat loss in movement of GTA torch.

Heat flux determined by Gaussian heat source model is validated as nature of distribution follows the experimental thermal cycle developed along the fusion boundary as well as along the longitudinal direction from fusion boundary.

Variation of thermal conductivity with time reveals that the property at higher temperature shows significant deviation (from $5.655 \mathrm{w} / \mathrm{m}-\mathrm{deg}$. C to $0.125 \mathrm{w} / \mathrm{m}$-deg) near the fusion zone $(\mathrm{z}=36 \mathrm{~mm})$ due to high temperatures obtained. It also depicts the acceptability of Carslaw-Jaeger's moving point heat source model with experimental investigation.

Specific heat based on thin plate model denotes the influence of heat affected zone on this parameter. Apart from $\mathrm{z}=36 \mathrm{~mm}$, it is approximately constant on other locations with respect to time.

Radiation heat loss in welding is crucial parameter in higher temperature $\left(400^{\circ} \mathrm{C}-1300^{\circ} \mathrm{C}\right)$ whereas at lower temperatures $\left(30^{\circ} \mathrm{C}-350^{\circ} \mathrm{C}\right)$ convective heat loss is dominating.

Total heat loss according to proposed correlation is matched with Vinokurov's empirical heat loss model and it can be useful for selection of proper materials with particular emissivity.

\section{REFERENCES}

1. Rosenthal D., "The theory of moving sources of heat and its applications in metal treatments", 1946, Trans. ASME, vol. 68, pp. 849 - 865.

2. Pavelic V. et al., 1969, "Experimental and computed temperature histories in gas tungsten arc welding of thin plates", Welding J. Research Supplement, vol. 48, pp. $295-305$ s.

3. Goldak J. A. et al., 1997, “Thermal stress analysis in solids near the liquid region in the weld: Mathematical modeling of weld phenomena", The Institute of Materials, pp. $543-570$.

4. Goldak J. A. and Akhlaghi M., "Computational Welding Mechanics", Springer Science+Business Media Inc., New York, USA, 2005, pp. 22 -23.

5. Little G. H. and Kamtekar A. G., 1998, "The effect of thermal properties and weld efficiency on transient temperatures in welding", Computers and Structures, vol. 68 , pp. 157 - 165.

6. Komanduri R. and Hou Z. B., 2000, "Thermal analysis of arc welding process: Part I. General solutions", Metallurgical and Materials Transactions B, vol. 31B, pp. 1353 - 1370 .

7. Komanduri R. and Hou Z. B., 2001, "Thermal analysis of arc welding process: Part II. Effect of thermophysical properties with temperature", Metallurgical and Materials Transactions B, vol. 33B, pp. $483-499$.

8. Gary D. et al., 2005, "Effect of welding speed, energy input and heat source distribution on temperature variations in butt welding", J. of Material Processing Technology, vol. 167, pp. 393 - 401.
9. Poorhaydari K. et al., 2005, "Estimation of cooling rates in the welding of plates with intermediate thickness", Welding Journal, pp. 148s - 155s.

10. Mousavi Akbari S. V. and Miresmaeili R., 2008, "Experimental and numerical analysis of residual stress distribution in TIG welding process for 304L stainless steel", J. of Material Processing Technology, vol. 208, pp. 383 - 394.

11. Goncalves C. V., Carvalho S. R. and Guimaraes G., 2010, "Application of optimization techniques and enthalpy method to solve a 3D inverse problem during a TIF welding process", Applied Thermal Engineering, vol. 30 , pp. 2396 - 2402.

12. Attarha M. J. and Sattari-Far I., 2011, "Study on welding temperature distribution in thin welded plates through experimental measurements and finite element simulation", J. of Material Processing Technology, vol. 211, pp. $688-694$.

13. Pathak C. S. et al., 2012, “Analysis of thermal cycle multipass arc welding”, Welding Journal, vol. 91, pp. $149 \mathrm{~s}-155 \mathrm{~s}$.

14. Tong Zhang et al., 2013, "A dynamic welding heat source model in pulsed current gas tungsten arc welding", J. of Material Processing Technology, vol. 213, pp. 2329 - 2338.

15. Dal Morgan et al., 2014, "A model comparison to predict heat transfer during spot GTA welding”, Int. J. of Thermal Sciences, vol. 75, pp. 54 - 64.

16. Ravisankar A. et al., 2014, "Influence of welding speed and power on residual stress during gas tungsten arc welding of thin sections with constant heat input: A study using numerical simulation ans experimental validation", J. of Manufacturing Process, vol. 16, pp. $200-211$.

17. Lee Hwa Teng and Chen Chun Te, 2011, "Predicting effect of temperature field on sensitization of alloy 690 weldments", Materials Transactions, vol. 52(9), pp. 1824 - 1831.

18. Carslaw H. S. and Jaeger J. S., 1959, "Conduction of Heat in Solids", Oxford University Press, $2^{\text {nd }}$ edition, Oxford, United Kingdom.

19. Quigley M B C et al., 1973, "Heat flow to the workpiece from a TIG welding arc", J. Phys. D: Appl. Phys., vol. 6, pp. 2250 - 2258.

20. Traidia A. and Roger F., 2011, "Numerical and experimental study of arc and weld pool behaviour for pulsed current GTA welding", Int. J. of Heat and Mass Transfer, vol. 54, pp. 2163 - 2179.

21. Jiji Latif M., "Heat conduction", Springer-Verlag Berlin Heidelberg, $3^{\text {rd }}$ edition, 2009, pp. $243-244$.

22. Desai R. S. and Bag S., 2014, "Influence of displacement constraints in thermomechanical analysis of laser micro-spot welding process", J. of Manufacturing Process, vol. 16, pp. 164 - 275.

23. Dieter George E., "Mechanical Metallurgy", McGraw Hill, $3^{\text {rd }}$ edition, pp. $75-77$. 